\section{REFERENCES}

1. Scagliotti GV, Parikh P, von Pawel J, et al. Phase III study comparing cisplatin plus gemcitabine with cisplatin plus pemetrexed in chemotherapy-naive patients with advanced-stage non-small-cell lung cancer. J Clin Oncol 2008;26:3543-51.

2. Sandler A, Gray R, Perry MC, et al. Paclitaxelcarboplatin alone or with bevacizumab for non-smallcell lung cancer. N Engl J Med 2006;355:2542-50.

3. Paez JG, Janne PA, Lee JC, et al. EGFR mutations in lung cancer: correlation with clinical response to gefitinib therapy. Science 2004;304:1497-500.

4. Lynch TJ, Bell DW, Sordella R, et al. Activating mutations in the epidermal growth factor receptor underlying responsiveness of non-small-cell lung cancer to gefitinib. N Engl J Med 2004;350:2129-39.

5. National Institute for Health and Clinical Excellence (2010) Gefitinib for the first-line treatment of locally advanced or metastatic nonsmall-cell lung cancer. TA192. London: National Institute for Health and Clinical Excellence. http:// guidance.nice.org.uk/TA192.

6. Pirker R, Pereira JR, Szczesna A, et al. Cetuximab plus chemotherapy in patients with advanced non-small-cell lung cancer (FLEX): an open-label randomised phase III trial. Lancet 2009;373:1525-31.

7. Inoue A, Kobayashi K, Usui K, et al. First-line gefitinib for patients with advanced non-small-cell lung cancer harboring epidermal growth factor receptor mutations without indication for chemotherapy. J Clin Oncol 2009;27:1394-400.

8. The National Lung Cancer Audit 2009. The NHS Information Centre, Leeds. 2009. http://www.ic.nhs.uk/ webfiles/Services/NCASP/audits\%20and\%20reports/ IC23090809 NHS IC Lung Cancer AUDIT 2009 Interactive for we web.pdf

9. Stolz D, Kurer G, Meyer A, et al. Propofol versus combined sedation in flexible bronchoscopy: a randomised non-inferiority trial. Eur Respir $J$ 2009:34:1024-30.

10. Thomas JSJ, Lamb D, Ashcroft T, et al. How reliable is the diagnosis of lung cancer using small biopsy specimens? Report of a UKCCCR Lung Cancer Working Party. Thorax 1993:48:1135-9.

11. Tremblay A, Marquette $\mathrm{CH}$. Endobronchial electrocautery and argon plasma coagulation: a practical approach. Can Respir J 2004;11:305-10.

12. Rintoul RC, Tournoy KG, El Daly H, et al. EBUS-TBNA for the clarification of PET positive intra-thoracic lymph nodes - an international multi-centre experience. J Thorac Oncol 2009:4:44-8.

13. Tournoy KG, Rintoul RC, van Meerbeeck JP, et al. EBUS-TBNA for the diagnosis of central parenchymal lung lesions not visible at routine bronchoscopy. Lung Cancer 2009;63:45-9.

14. Paone G, Nicastri E, Lucantoni G, et al. Endobronchial ultrasound-driven biopsy in the diagnosis of peripheral lung lesions. Chest 2005;128:3551-7.

15. Yoshikawa M, Sukoh N, Yamazaki K, et al. Diagnostic value of endobronchial ultrasonography with a guide sheath for peripheral pulmonary lesions without $\mathrm{X}$-ray fluoroscopy. Chest 2007;131:1788-93

16. Kurimoto N, Miyazawa T, Okimasa S, et al. Endobronchial ultrasonography using a guide sheath increases the ability to diagnose peripheral pulmonary lesions endoscopically. Chest 2004;126:959-65.

17. Oki M, Saka H, Kitagawa C, et al. Endobronchial ultrasound guided transbronchial biopsy using novel thin bronchoscope for diagnosis of peripheral pulmonary nodules. J Thorac Oncol 2009;4:1274-7.

18. Yamada N, Yamazaki K, Kurimoto N, et al. Factors related to diagnostic yield of transbronchial biopsy using endobronchial ultrasonography with a guide sheath in small peripheral pulmonary lesions. Chest 2007:132:603-8.
19. National Institute for Health and Clinical Excellence (2008) Endobronchial ultrasound-guided transbronchial needle aspiration for mediastinal masses. IPG254. London: National Institute for Health and Clinical Excellence. http://guidance.nice.org.uk/IPG254.

20. National Institute for Health and Clinical Excellence (2010) Endobronchial ultrasound-guided transbronchial biopsy for peripheral lung lesions. IPG337. London: National Institute for Health and Clinical Excellence. http://guidance.nice.org.uk/IPG337.

21. Ou SH, Zell JA. Carcinoma NOS is a common histologic diagnosis and is increasing in proportion among non-small cell lung cancer histologies. J Thorac Oncol 2009;4:1202-11.

22. Moller H, Shack L, Moran A. Lung cancer in the north west. Manchester: North West Cancer Intelligence Service, 2008

23. Loo P, Thomas S, Fyfe M. Immunohistochemical diagnosis of 'non-small cell lung cancer, not otherwise specifiable' in bronchial biopsy specimens. J Thorac Oncol 2009;4(Suppl 1):s340.

24. Rana D, O'Donnell M, Malkin A, et al. A comparative study: conventional preparation and thin-prep2000 in respiratory cytology. Cytopathology 2002;12:390-8

25. Mok TS, Wu YL, Thongprasert S, et al. Gefitinib or carboplatin-paclitaxel in pulmonary adenocarcinoma. N Engl J Med 2009;361:947-57.

26. Fukui T, Ohe $\mathrm{Y}$, Tsuta $\mathrm{K}$, et al. Prospective study of the accuracy of EGFR mutational analysis by high-resolution melting analysis in small samples obtained from patients with non-small cell lung cancer. Clin Cancer Res 2008;14:4751-7.

27. Smouse JH, Cibas ES, Janne PA, et al. EGFR mutations are detected comparably in cytologic and surgical pathology specimens of nonsmall cell lung cancer. Cancer Cytopathol 2009:117:67-72.

\title{
Imaging in lung cancer: recent advances in PET-CT and screening
}

\section{David R Baldwin}

Lung cancer is probably the most intensely imaging dependent sub-specialty within respiratory medicine. Historically chest physicians have had close involvement with imaging. The development of mass miniature chest radiographs is attributed to Manuel Dias de Abreu, a Brazillian pulmonologist $^{1}$ and in conjunction with providing a tuberculosis service, chest physicians have reported mass miniature chest radiographs, independent of radiologists. Although the latter is now neither appropriate or indeed the case, in lung cancer, chest physicians along with other

Correspondence to David R Baldwin, Consultant Respiratory Physician, Department of Respiratory Medicine, David Evans Research Centre, City Hospital Campus, Nottingham University Hospitals, Nottingham NG5 1PB, UK; david.baldwin@nuh.nhs.uk clinicians within the cancer multidisciplinary team (MDT) rely heavily on imaging and, aided by the accessibility of images afforded by the Picture Archiving and Communication System (PACS) are becoming increasingly expert. Furthermore, chest physicians are using imaging more for their own diagnostic and therapeutic procedures; in particular transthoracic and endobronchial ultrasound. It is axiomatic therefore that a radiologist who is firmly committed to the cancer MDT makes an enormous contribution to an effective care pathway. Thus any new development in imaging will have a considerable impact on lung cancer clinicians' clinical practice whether they deal principally with diagnosis and staging (chest physicians and radiologists) or treatment (oncologists and thoracic surgeons).
Over the last 10 years there have been important developments in the lung cancer care pathway from early diagnosis through diagnosis and staging and to treatment, many of these driven by improved imaging. It is necessary to have a clear idea about the performance of an imaging test (or any test) to understand how a result should influence management. A self-evident point about imaging tests is that because they do not sample tissue, they tend to yield a greater number of false positive and false negative results and therefore have a lower specificity and negative predictive value compared with minimally invasive tests. Indeed, as imaging tests improve their sensitivity the place of tests that provide biopsy samples is more about excluding benign disease than confirming malignancy. ${ }^{2-5}$

The central role of multi-detector CT (MDCT) with contrast administration as a test early on in the lung cancer diagnostic and staging pathway is now firmly established and is essential in most patients to guide the next diagnostic test. ${ }^{6}$ Thus most fast-track lung cancer services ask for CT scans prior to the first outpatient 
consultation. CT is a sensitive test to detect lung cancer but not specific, especially if staging information is required. ${ }^{7-10}$ Similarly, the added information provided by FDG-PET scanning has led to universal use in lung cancer pathways, especially where patients are potentially suitable for treatment with curative intent. However, as data accumulate, the limitations of this test are becoming clear. PET-CT is a good example of a test that has a high sensitivity for lung malignancy ${ }^{8} 9$ and is good at excluding macroscopic disease (except in the brain). However, despite a negative PET-CT, there remain approximately $20 \%$ of patients who present with metastatic disease after what was felt to be curative treatment of early stage disease (arguably important to include when classifying patients who are 'true negatives'). ${ }^{10} \mathrm{PET}$ CT is also a sensitive test for lymph node involvement, which is, as we are reminded in this issue of Thorax, ${ }^{11}$ (see page 287) an important and independent prognostic factor. Studies have shown that a negative PET-CT of significantly enlarged nodes on CT ( $\geq 10 \mathrm{~mm}$ short axis) still carries a $15 \%$ risk of being a false negative. ${ }^{89}$ A further paper in this issue has confirmed that PETCT cannot be used to exclude nodal disease where nodes are enlarged on CT. However Fischer et al ${ }^{12}$ (see page 294) also showed that where nodes are not significantly enlarged on CT, the false negative rate of PET-CT was only 4\% (only one out of 29 patients) This finding provides strong support for the currently recommended approach that where there are no significantly enlarged lymph nodes on CT and no significant FDG uptake on PET, treatment with curative intent should be offered without further preoperative mediastinal staging but with systematic nodal dissection where treatment is surgical. ${ }^{13}$ When mediastinal nodes are large, further staging is clearly required, irrespective of the findings of PET-CT. A recent randomised trial of combined endobronchial and endoesophageal ultrasound needle aspiration (EBUS and EUS) versus mediastinoscopy has shown that the approaches are equivalent (and when combined better than either alone). ${ }^{14}$ The study by Fischer et al is supportive of these findings. ${ }^{12}$ In the immediate future, decisions about which is offered and whether negative EBUS/EUS results are followed by surgical staging will depend on local expertise and audited test performance.

PET-CT may also provide important help in the vexed area of incidentally identified solitary pulmonary nodules. Small lung nodules are now encountered more frequently since the widespread use of
CTPA for investigation of suspected pulmonary embolism. Help with how to manage these incidentally found nodules is available from the CT screening studies that have published their preliminary findings using different, safer and more efficient follow-up protocols. ${ }^{15-17}$ In all of the published studies, including those with a high prevalence of lung cancer, there are many more benign than malignant nodules detected. PET-CT and measurement of volume doubling time (VDT) may serve to reduce repeat scans and reduce potential harm. The paper by Ashraf et al ${ }^{18}$ (see page 315) shows that, for lung nodules 5-15 mm diameter (non-solid up to $20 \mathrm{~mm}$ ), PET-CT and VDT yield identical sensitivities and specificities (71\% and 91\% respectively) and that the combination of the two is better. However, in screening trials, costs and harms are essential considerations and so the authors' recommendation to use VDT and PET as parallel tools in screening trials needs to be tested in trials capable of defining whether this approach improves cost effectiveness. Until these are available, the suggestion by Gould $^{19}$ (see page 277 ) that malignancy should be assumed to be present if VDT is $<365$ days and/or FDG uptake on PET-CT is greater than the mediastinal blood pool seems sensible. However, the routine use of PET-CT in very small nodules may add considerable cost for only a small incremental benefit.

The protocol for the first UK randomised controlled trial of the use of CT-screening for lung cancer (UKLS) is published in this issue of Thorax. ${ }^{20}$ The management algorithm of detected lung nodules heavily relies on VDT but does include PET as part of the work-up once VDT is found to be $<400$ days. This is thought to be the most cost-effective approach because PET-CT, expensive in the UK, is used as a downstream investigation for nodules that meet either baseline volume/size criteria or show a VDT of $<400$ days. The study will measure the proportion of benign nodules that are evaluated by an invasive approach as part of the harms evaluation. From Ashraf et al, when VDT and PET were positive, malignancy was virtually certain but when they differed, the prevalence of malignancy was $57 \%$, with 4 cancers being 'missed' by PET-CT and 4 by VDT. UKLS would thus miss some cancers by using VDT only in the screen. However, it is not known how these nodules that show no significant growth influence mortality, the main outcome measure of screening trials. Biologically they may be more likely to be indolent and therefore detected on subse- quent screens at a stage when still curable. UKLS uses similar criteria to those used in the Dutch-Belgium CTscreening study and is designed so that the mortality results of these, the largest of the European screening studies, can be reported together. The interim results of the NELSON study were reported in $2009{ }^{15}$ and show that while most lung cancers were detected by this method, a proportion was detected at subsequent screening rounds. These were either incident nodules or those that were previously too small to characterise. The crucial question will be whether those cancers would be detected more economically by a longer interval between screens without missing potentially curable cancer.

Many centres in the UK use a modification of the Fleischner Society Guidelines on the management of solitary pulmonary nodules and this involves many repeat CT scans, the majority of which (at least 95\%) will not detect cancer. ${ }^{21}$ The approach adopted by the use of low dose CT and measuring VDT may reduce the number of repeat scans and radiation dose, and is evidence-based, albeit in high-risk populations. Thus developments in imaging are again suggesting a new pathway-this time for the management of incidentally detected pulmonary nodules. As with other developments, the use of volume measurement software is likely to become widely available and the more straightforward algorithm will diminish confusion among those less familiar with the subject.

Clinicians and commissioners will be reassured that PET-CT improved staging accuracy in the per-protocol population, ${ }^{12}$ and will be happy to accept the resultant reduced risk of futile Thoracotomy. ${ }^{3}$ Could there be additional benefits? One possibility is that the SUV provides independent prognostic information. There is accumulating evidence that it does, ${ }^{22}$ but the critical SUV level has not been defined nor is it clear how this information should alter management. For example, it may be that patients with complete resections and high SUV should have adjuvant chemotherapy as the potential for metastasis is high. In contrast, patients with low or intermediate SUV should perhaps have more aggressive treatment with curative intent than their lung cancer stage would ordinarily suggest as biologically these cancers may have less metastatic tendency. This additional information is likely to be particularly helpful in otherwise borderline patients being considered for potentially curative treatment with surgery or radical radiotherapy. Although a response in SUV following treatment is considered 
favourable, we do not know if this is a valid method of predicting outcome and response in SUV is not yet a competitor to the established RECIST criteria for tumour response. $^{2324}$

A key development in lung cancer imaging occurred in November 2010 when the US National Cancer Institute announced that the National Lung Screening Trial, a randomised trial of lowdose CT versus chest radiography, had achieved its primary end point of a reduction in mortality of $20 \%$ in the CT arm and has therefore been stopped. ${ }^{25}$ The trial, that enrolled 53456 people, is the only screening trial to show a mortality benefit. The full publication will appear in the next few months and report important secondary outcomes including cost-effectiveness and harms. The other ongoing studies with different designs and in different healthcare systems, and may be important in determining the best approach to screening. ${ }^{16-18}$ With this important development it seems that unprecedented major improvements in mortality from lung cancer are achievable and with this comes the certainty that the problem of the small pulmonary nodule will become increasingly common.

Competing interests I am lead physician on the UKLS trial.

Provenance and peer review Commissioned; not externally peer reviewed.

Thorax 2011:66:275-277.

doi:10.1136/thx.2010.149153

\section{REFERENCES}

1. Alves Fliho M. Manoel de ABREU, M.D. 1892-1962. Am J Roentgenol Radium Ther Nuclear Med 1962;87:1167-9. ISSN 0002-9580.

2. Baldwin DR, Eaton T, Kolbe J, et al. Management of solitary pulmonary nodules: how do thoracic computed tomography and guided fine needle biopsy influence clinical decisions? Thorax 2002;57:817-22.
3. Chang CY, Tzao C, Lee SC, et al. Incremental value of integrated FDG-PET/CT in evaluating indeterminate solitary pulmonary nodule for malignancy. Mol Imag Biol 2010;12:204-9.

4. Herder GJ, van Tinteren H, Golding RP, et al. Clinical prediction model to characterize pulmonary nodules: validation and added value of 18ffluorodeoxyglucose positron emission tomography. Chest 2005; 128:2490-6.

5. Sortini D, Maravegias K, Feo CV, et al. Repeat needle biopsies combined with clinical observation are safe and accurate in the management of a solitary pulmonary nodule. Cancer 2005; 104:664-5.

6. Laroche C, Fairbairn I, Moss $\mathrm{H}$, et al. Role of computed tomographic scanning of the thorax prior to bronchoscopy in the investigation of suspected lung cancer. Thorax 2000;55:359-63.

7. Kramer H, Groen $\mathrm{HJ}$, Kramer $\mathrm{H}$, et al. Current concepts in the mediastinal lymph node staging of non small cell lung cancer. [Review] [97 refs]. Ann Surg 2003;238:180-8.

8. Gould MK, Kuschner WG, Rydzak CE, et al. Test performance of positron emission tomography and computed tomography for mediastinal staging in patients with non-small-cell lung cancer: a metaanalysis. [Review] [109 refs]. Ann Intern Med 2003;139:879-92.

9. De Wever W, Meylaerts L, De Ceuninck L, et al. Additional value of integrated PET-CT in the detection and characterization of lung metastases: correlation with CT alone and PET alone. Eur Radiol 2007:17:467-73.

10. Kelsey CR, Marks LB, Hollis D, et al. Local recurrence after surgery for early stage lung cancer: an 11-year experience with 975 patients. Cancer 2009;115:5218-27.

11. Wisnivesky JP, Arciniega J, Mhango G, et al. Lymph node ratio as a prognostic factor in elderly patients with pathological N1 non-small cell lung cancer. Thorax 2011;66:287-93.

12. Fischer BM, Mortensen $\mathrm{J}$, Hansen $\mathrm{H}$, et al. Multimodality approach to mediastinal staging in non-small cell lung cancer. Faults and benefits of PET-CT—a randomised trial. Thorax 2011;66:294-300.

13. Lim $\mathbf{E}$, Baldwin D, Beckles $\mathrm{M}$, et al. Guideline on the radical management of patients with lung cancer. Thorax 2010;65(Suppl III):iii1-27.

14. Annema JT, van Meerbeeck JP, Rintoul R, et al Mediastinoscopy vs Endosonography for mediastinal node staging of lung cancer: a randomised trial. JAMA 2010;304:2245-52.
15. van Klaveren RJ, Oudkerk M, Prokop $M$, et al Management of lung nodules detected by volume CT scanning. N Engl J Med 2009;361:2221-9.

16. Pedersen JH, Ashraf $H$, Dirksen A, et al. The Danish Randomized Lung Cancer CT Screening Trial-Overall Design and Results of the Prevalence Round. J Thorac Oncol 2009;4:608-14.

17. Infante M, Cavuto S, Lutman F, et al. A Randomized Study Of Lung Cancer Screening With Spiral Computed Tomography: three-year results from the DANTE trial. Am J Respir Crit Care Med 2009; 180:445-53

18. Ashraf H, Dirksen A, Loft A, et al. Combined use of PET and volume doubling time in lung cancer screening with low dose CT. Thorax

2011;66:315-19.

19. Gould MK. Evaluation of screening-detected lung nodules: minimising the risk of unnecessary biopsy and surgery. Thorax 2011;66:277-79.

20. Baldwin DR, Duffy SW, Wald NJ, et al. United Kingdom Lung Screen (UKLS) Nodule Management Protocol: Modelling of a Single Screenin Randomised Controlled Trial of Low-Does CT Screening for Lung Cancer.

21. MacMahon H, Austin JH, Gamsu G, et al; Fleischner Society. Guidelines for management of small pulmonary nodules detected on CT scans: a statement from the Fleischner Society. Radiology 2005:237:395-400.

22. Berghmans T, Dusart $M$, Paesmans $M$, et al. Primary tumor standardized uptake value (SUVmax) measured on fluorodeoxyglucose positron emission tomography (FDG-PET) is of prognostic value for survival in non-small cell lung cancer (NSCLC): a systematic review and meta-analysis (MA) by the European Lung Cancer Working Party for the IASLC Lung Cancer Staging Project. [Review] [46 refs]. $J$ Thorac Oncol 2008;3:6-12.

23. Therasse P, Arbuck SG, Eisenhauer EA, et al. New guidelines to evaluate the response to treatment in solid tumors. European Organization for Research and Treatment of Cancer, National Cancer Institute of the United States, National Cancer Institute of Canada. J Natl Cancer Inst 2000;92:205-16.

24. Wong CY, Schmidt J, Bong JS, et al. Correlating metabolic and anatomic responses of primary lung cancers to radiotherapy by combined F-18 FDG PET-CT imaging. Radiat Oncol 2007;2:18.

25. http://www.cancer.gov/newscenter/pressreleases/ NLSTresultsRelease.

\section{Evaluation of screening-detected lung nodules: minimising the risk of unnecessary biopsy and surgery}

\author{
Michael K Gould
}

Screening for lung cancer has a long and controversial history. Successful screening

Correspondence to Michael K Gould, Department of Medicine (Pulmonary and Critical Care) and Preventive Medicine, Keck School of Medicine of the University of Southern California, 2020 Zonal Avenue, IRD Room 715 Los Angeles, CA 90033, USA; mgould@usc.edu is predicated on two fundamental principles. ${ }^{1}$ First, the screening test should be able to detect disease in an early preclinical phase before symptoms develop. Second, treatment should be available and more effective when provided during the preclinical phase. On the surface it would appear that screening for lung cancer passes both of these tests, given our experience with treating 'early' versus 'late' stage lung cancer that is clinically detected. However, if we acknowledge that at least some cases of clinically detected stage I and II lung cancer might represent disease that is relatively indolent biologically as opposed to 'early', then the possibility exists that early detection will not alter the natural history of lung cancer and result in more frequent cure. Fortunately, the hypothesis that lung cancer screening with CT scanning reduces mortality is currently being evaluated in several large randomised controlled trials in both the USA and Europe. ${ }^{2-6}$ 